\title{
Emotions in Charter School Teaching: Three Stories From Year One
}

\author{
Miriam Hirsch
}

\begin{abstract}
The purpose of this paper is to illuminate the experiences of two recent graduates from an undergraduate initial certification educator preparation program (EPP) who began their first year working for a charter school in a large urban city. Their background in the constructivist-oriented EPP contrasts sharply with the philosophy and instructional practices of the charter school. The extreme nature of this particular context sheds light on the teacher induction process and raises questions about enhancing new teachers' adaptive capacities and emotional resilience to work through professional dissonance in the first years. These stories suggest that new teachers may benefit from additional training in communication skills and emotion management in the navigation of school workplace dilemmas.
\end{abstract}

\section{Background}

The teachers in this study attended a small undergraduate EPP in an urban city. The program is housed in an all-female college for Jewish women. While the EPP is a CAEP-accredited program, most of the program graduates typically work in Jewish day schools teaching in early childhood or elementary classrooms. The EPP offers all required pedagogical methods courses, fieldwork and student teaching experiences, and collaborates with Lincoln Center Education to integrate arts-based learning experiences into the college classroom. The program espouses constructivist pedagogies and privileges firsthand sensory learning and discovery methods to build lifelong skills and professional dispositions for inquiry, reflection, and advocacy. The new teachers joined TFA immediately after graduation and were both accepted to work in different charter schools that were part of the same larger charter school organization.

\section{Theoretical Framework}

This study is informed by the literature of principled resistance and emotions in teaching. Achinstein and Ogawa (2006) find that principled resistance in high-control environments may bring new teachers professional isolation and contribute to teacher attrition. In contrast, Altinyelken (2013) draws upon Gitlin and Margonis's (1995) notion of resistance as "good sense," when resistance arises from deep commitment to one's professional conception of good education and good teaching. The author argues that resistance should not be viewed as a "problem" to overcome, but can play a crucial role in curricular implementation.

LEARNing Landscapes | Spring 2018, Vol. 11 No. 2 | 167 
Hargreaves (2001) examines the emotional under-life of teaching and how "teachers' emotions are shaped by the variable and changing conditions of their work" (p. 1058). Hargreaves distinguishes "several forms of emotional distance and closeness that can threaten emotional understanding among teachers, students, colleagues, and parents" (p. 1061). The five emotional geographies (socio-cultural distance, moral distance, professional distance, physical distance, and political distance) shape emotions teachers may experience in school relationships. For example, professional distance between the school culture and the new teacher's emergent teaching philosophy can be an uncomfortable stretch thereby magnifying anxiety, conflict, and frustration. Emotional navigation (Reddy, 2001) through these waters may increase stress as the first-year teachers grapple with unfamiliar strictures and constraints at odds with their preparation and training.

\section{Review of the Literature}

Within the literature on charter schools, most studies focus on the effectiveness of the schools in terms of student achievement on standardized accountability assessment measures (Angrist, Pathak, \& Walters, 2013; Dobbie \& Fryer, 2011, Hoxby \& Rockoff, 2005; Hoxby, Muraka, \& Kang, 2009). In 2015, The Center for Research on Education Outcomes (CREDO), housed in Stanford University, reported that the typical student in an urban charter school receives the equivalent of 40 additional days of learning growth in math and 28 days of additional growth in reading (Mead, 2015). However, in other suburban and rural areas there was no difference between charter school performance and that of the typical public school. For example, in Michigan where charter schools have been around for almost 20 years, 80\% of the charters demonstrate academic achievement below the state average in reading, and $84 \%$ below the state average for math (Ingall, 2017). Research also shows increased high school graduation rates from charters beyond typical public schools in some cities (National Alliance for Charter Schools, 2016), but likewise, these effects are inconsistent, and even below the national rate in other places across the United States (McLaughlin, 2016).

Independent of student performance data, the firsthand lived experience of the particular teacher in the charter school environment is typically missing from the data. Schmidt and Datnow (2005), in their study of five comprehensive school reform models, include one charter school organization and find this model raised the most emotion and conflict for teachers. "I resent the lack of freedom I have in delivering the information" (p. 958), says one teacher. Another teacher comments: "It's not that I don't like the program ... it's just that it's hard on you as a person" (p. 959). This study builds upon the scholarship by focusing on the lived experience of two novice teachers working in a high-pressure charter environment and the ambiguity faced by their teacher (the author) in conducting the research and confronting the reality of the charter school environment. It is important to acknowledge that this research is particular to these participants and does not claim to reflect on all charter school environments. 


\section{Mode of Inquiry}

This study employs the qualitative research methodology of portraiture (Lawrence-Lightfoot, 2005) to provide a descriptive and interpretive account of the experience of the first-year teachers. "The portraitist is active in selecting the themes that will be used to tell the story, strategic in deciding on points of focus and emphasis, and creative in defining the sequence and rhythm of the narrative" (p. 10). The portraits were composed independently from interview, observation, and artifact data, but insight from one reflected onto the other with "criss-crossed reflection" (Spiro, Vispoel, Schmitz, Samarapungavan, \& Boerger, 1987). While it was not part of the initial research protocol, I decided to craft my own self-portrait as the research story continued. I found myself jettisoned from pride to dismay to concern as I weighed the merit of the teaching and learning experiences for these new teachers in the particular charter school environment.

\section{Data Sources}

Data sources include multiple in-depth interviews and observations of each participant in their workplace. In addition, field notes, journaling, and concept mapping contributed to the crafting of the portraits. The participants engaged in member checking and allowed the researcher access to lesson plans, professional evaluation rubrics, and student worksheets. The researcher is a former teacher of both participants, so there is a level of trust and communication borne from personal history. "The portraits are shaped through dialogue between the portraitist and the subject" (Lawrence-Lightfoot \& Davis, 1997, p. 3). Both participants expressed concern about saying anything that could impede their professional advancement and occasionally asked the researcher to keep certain incidents "off the record." Honoring this request, yet still communicating the story, is an inherent tension embedded in the work. "One of the most powerful characteristics of portraiture is its ability to embrace contradictions, its ability to document the beautiful/ugly experiences that are so much a part of the texture of human development and social relationships" (Lawrence-Lightfoot, 2005, p. 9).

\section{Findings}

This research generated three stories: the stories of Paige and Penny (pseudonymous), the teachers, and the story of the author who found herself in uncertain terrain waffling between curiosity and critique as she delved into her own experience in capturing and curating the stories of her former students.

\section{Paige}

Paige began her six-week TFA training in Philadelphia full of anticipation and optimism. Even though she had come from an EPP and passed the edTPA exam, the program was challenging. "I felt like going in I had a pretty good leg up in the game, but when I got there I just didn't realize how 
much I still had to learn." She worked hard preparing lessons to teach fifth graders in summer school. The most frustrating part of the experience for her was classroom management:

This isn't what I am used to, and this isn't the type of teaching I am used to doing and I don't necessary agree with it and I don't necessarily want to be doing this type of management and I don't want to be saying these things and doing these things, but what I have to do is pretty much "suck it up for the summer."

Although exhausted, Paige felt supported by the quality and commitment of the TFA community. "We had really, really trained skilled professionals teaching us." By the end of the training, Paige had come to a working understanding of the TFA way.

They gave me really good feedback and I would say that by the end of it I was like I understand . . . I understand why I did it, because my kids got a lot out of it and I could definitely see the differences when I was managing the way they wanted me to and doing the things they wanted me to. I definitely saw growth coming out of it. So in the end of the day, even if I didn't necessarily agree with it, I was like, "this is what I am going to do right now, because . . this is what I need to do."

Paige went directly from the TFA training into 2.5 week professional development by the charter school organization where she had to unlearn a lot of what she had just spent the summer mastering.

I got a lot of flak for the first couple of weeks ... they were like, as much as you learned this in TFA, that is not how we want you to do this here, because charter schools are pretty particular about the way they are run, and especially because they believe that the way that they need to run is the way that they are going to be able to keep their charter and have success. So obviously, I wasn't going to fight that, and I wasn't interested in fighting it, I just had to comply and learn their way.

The pay and graduate school benefits were some of the reasons why she entered TFA, but Paige had no idea when she applied to the program that she was responsible for securing a job as her TFA placement. "The process was pretty brutal . . getting into TFA was easy compared to the actual process of getting a job." She went through four interviews until she was offered a second grade position; she accepted knowing little about the demands and expectations of charter school.

I didn't know anything . . . I had never been to a charter school before, I had no idea . . . we have a much different way of management, it is very military I would say, compared to anything you have seen in any public school, even just the way that they have to stand up and push their chairs in to line up at the door.

Paige submits a weekly pacing calendar, but doesn't write lesson plans because they are all scripted. Each member of the grade team is responsible for downloading the documents (lesson plans, student packets) for one subject area and submitting in advance for copying. She is observed once a week by both her instructional coach and grade team leader, and every six weeks by her TFA mentor. The format of the instruction (I do, we do, you do) doesn't vary regardless of the subject area: The teacher models the skill, the students practice the skill together, and then they complete independent work. 
Before the December break, she and her second grade students were struggling: "I am one person, and there are 18 of them that have 18 really, really intense needs in different ways." Her students' scores were not as high for the ELA assessment as the school wanted.

I was like, "Well, there is a reason for that because there is like one of me and let's say six of them that are receiving services" .. I I sat with one of my students the other day and just coached him through writing, because he just can't, he can't get the stamina and there are 17 others that still needed me.

By March, Paige's morale had sunk. "I would say my opinion on charter schools has definitely like decreased . . . any positivity toward them has definitely decreased recently." The management system, which requires that the students sit with their hands folded tracking the speaker or receive warnings, was getting to her.

I am not comfortable with this way I have to discipline my students, I do it simply because that is the expectation and I am held to that. And I do get, I wouldn't say graded, but when I get observed, my feedback is all based on like, managm- a lot of it is based on management and things like that, so I do have to obviously do it. I don't . . I I am becoming more and more upset by having to do it as the year goes on.

During a formal review that month, her principal said that she was "underwhelmed by Paige's urgency." Paige thought she was working so hard; that she was not meeting the expectations of the school was emotionally distressing. Ultimately, Paige gave up her prep to work with low performing students, convincing the administration of her "urgency." Although she admits, "I hate what I have become, this is what I need to do to keep my job."

\section{Penny}

Penny really enjoyed the TFA training in Philadelphia. Having gone to a traditional public elementary and high school, she found the diversity of the TFA recruits inspiring and welcoming. She especially loved the children and found her calling in the opportunity to make a difference in the lives of her students. However, she was bemused that despite her background, coming from an EPP, which was in contrast with most of the TFA members, she had to relearn lesson planning and curriculum design from "their approach." She appreciated the feedback from her coaches and mentors, and was excited to begin her year teaching in the charter school as a literacy specialist. However, at the school she had to unlearn the TFA approach, and follow the script of the charter school teaching style.

Penny's position was not that of classroom teacher. She is officially a learning specialist. She was given a small room to work in and was allocated different small groupings of math and literacy students throughout the day. She taught social studies and science to different grade one classes, but was not an official classroom teacher. Nonetheless, Penny worked mindfully to make her space warm and inviting and establish relationships with her students. But, having this focus on relationship building at the beginning of year one became a huge problem. 
As a result of her relationship building practices without ample attention to the strict management system, as described earlier with Paige's narrative, Penny's authority in the classroom eroded along with her confidence. She was reminded again and again to tighten up her warnings, tracking, and overall structure, and battled her inner voice of resistance in order to improve her standing with supervisors and make her classroom a more effective environment for teaching and learning.

Unfortunately, the message was not delivered in a supportive way and Penny began to doubt her choice of vocation, questioning her decision to teach. The culture of the school is highly professional, or as Penny dubbed it, "professional to the point where it is just like a cold, working atmosphere." The principal calls his office "The War Room," and the intense focus on data driven instruction at all costs to "win the war" mutes the voices of care, concern, and support that Penny requires in her first year of teaching. At the lowest point she asks, "Why am I here?"

When I observe her teach, I noticed her struggle between following the script and motivating the students. This desire to build their confidence and make them believe in themselves was her reason to join TFA. She was actually the impetus for Paige to sign up, convincing her to apply. Yet, year one found Penny as the non-classroom teacher, in a school that did not seem to believe in her abilities or adequately support her professional development with sensitivity and respect.

In the classroom, she hits many of the marks with the academic language and fast pace the instructional approach requires, yet her conscious awareness of the misconceptions and errors of her students is lost in her struggle to perform the lines as the school demands.

An example comes from a choral call and response that I observed; the lesson was on 2D geometric shapes and the teacher is holding up a small plastic trapezoid.

This is a trapezoid, a what? A trapezoid.

A trapezoid has two parallel sides. A trapezoid has two parallel sides.

A trapezoid has ... They answer, "Two parallel sides."

How many sides does a trapezoid have? "Two," answers the class.

Penny realizes her mistake, but the script has not anticipated this misconception. She does not have the scripted lines on the lesson plan in front of her to help the students parse the difference between the attributes of the trapezoid shape. How does one explain in simple language to struggling first graders that four sides and two sets of parallel sides are not in contradiction?

Visiting the school and talking with my former students, I struggle with my opinion that for the most part the curriculum is not developmentally appropriate. Students work hard to achieve test scores that will make the school proud, and reassure the administration of the teacher's urgency and commitment, but the lack of manipulatives, interactive experiences, stations, or child-centered learning, is viscerally hard to swallow. Yet, I do not directly communicate my displeasure with either Paige or Penny. 
Instead, I ask about hands-on learning repeatedly, so I am sure they know; but I try to squelch my opinions, in order to understand their experience.

By the end of year one, however, Penny has amped up her day by creating a special lunch lesson for select students called the, "What I can be project?" She brings in magazines, scissors, and glue, and works with them to create a book and poster about their dreams and goals. On her own time, she creates a space where she simultaneously honors her own philosophy of why she entered the profession, and shows the administration she is committed to the children. She also signs up to tutor third graders after school in preparation for the state tests.

But by the end of the year, she has somewhat figured out how to work within the constraints of the environment. "I respect what they do and I do what they ask me, but I have "Penny-i-fied it." Yet, she is still feeling pressure, concluding: "They are always watching you . . It is hard to consistently be positive."

\section{Self-Portrait}

I was really excited that two of our graduates were joining TFA. I felt that it was good impact data for our EPP that we had two students out of their cohort of 15 who wanted to "make a difference" in the lives of at-risk youth. I was proud of their choice and the commitment it takes to tackle the demands of the TFA program. Both quickly passed all the state certification exams, including the rigorous edTPA, and I was pleased that they were prepared enough to do so under the time restraints placed by the organization which gave them approximately six weeks after graduation to "get it done."

Never having set foot in a charter school prior to initiating this study, I was excited to see the school setting I had read and heard so much about. It took close to six months to receive the necessary three IRB approvals from my institution, TFA, and the urban city department of education.

Curiously, I had thought that the cultural differences between the new teacher, coming from her Orthodox Jewish background, and her students, would provide a fertile area of inquiry. Table 1 provides background demographic detail of each school, while preserving anonymity. According to the NYC Department of Education School Performance Dashboard for the 2017 academic year, the economic need index in Paige's school (School A) is 78\%, and 74\% in Penny's school (School B). In addition, the student ethnicity of the two schools where the participants teach is recorded as over $90 \%$ Black or Hispanic. To my surprise the new teachers reported little socio-cultural dissonance regarding the demographic differences. 


\section{Table 1}

\section{Demographics of Student Population ${ }^{1}$}

\begin{tabular}{|l|l|l|}
\hline & School A & School B \\
\hline Enrollment & 291 & 490 \\
\hline Asian & $0 \%$ & $2 \%$ \\
\hline Black & $46 \%$ & $39 \%$ \\
\hline Hispanic & $51 \%$ & $57 \%$ \\
\hline White & $1 \%$ & $1 \%$ \\
\hline $\begin{array}{l}\text { Students } \\
\text { with } \\
\text { Disabilities }\end{array}$ & $11 \%$ & $11 \%$ \\
\hline $\begin{array}{l}\text { Self- } \\
\text { Contained }\end{array}$ & $0 \%$ & $1 \%$ \\
\hline ELL & $16 \%$ & $18 \%$ \\
\hline $\begin{array}{l}\text { Economic } \\
\text { Need } \\
\text { Index }\end{array}$ & $78 \%$ & $74 \%$ \\
\hline
\end{tabular}

However, they were most seriously affected by the particular nature of the charter school culture and the ensuing expectations of teaching in this extreme setting. I discovered that our graduates are well prepared to teach most subject matter content, but were ill prepared to implement the strict classroom management system upon which the charter school system was structured. In addition, a second but related disconnect between our EPP and this schooling context concerns the program completers' readiness and resilience with relationship management dilemmas. Next, I briefly address each concern.

Professional dissonance. The charter school classroom management system stands in stark contrast with the private and traditional public schools where the teacher candidates are placed for fieldwork and student teaching. In fact, the culture of the charter school stands in contrast with any school I have ever visited. Distinctive features, some as mentioned earlier in the teachers' stories, include:

- Students must sit with hands folded on desk and feet flat on the floor facing forward at all times ("scholar position").

- Students must visually track the speaker at all times.

- All lessons are scripted.

- Teachers do not plan lessons; they download the lessons for the week in each subject area.

- Students do not ask questions.

- All lessons in all subject areas follow the format of direct instruction ("I do, we do, you do") whereby the teacher models the skill, guides the students in practicing the skill, and then the students independently perform the skill.

Our EPP, most educational scholarship, and conventional wisdom advance the development of socialemotional learning through more self-regulatory and humanist strategies, particularly for younger learners, such as grades one and two in this study. At the beginning of my research study, I found the choreography of the classroom interesting. Students hold their hands and forearms parallel, and clap the answer to the multiple-choice questions of their exit assessment tickets. But, they do this every day the exact same way. All transitions are choreographed and executed with formal precision, such as pushing 
in chairs and marching into line. The regularity and standardization of the schooling is both impressive and depressing. I saw young children drop pencils repeatedly, so they could bend and pick them up. I saw many students with untied shoes, and I worried that they didn't know how to tie them and would trip because shoe tying was not part of the curriculum. I found myself torn between admiration for the choreography and disappointment at the lack of animation, laughter, and life in the room.

To be fair, I wasn't there enough to know that those things never happened. But I was there enough for them to happen and I did not see it in either classroom.

The friction between what we teach in the EPP and the practices of the charter school is provocative. I wondered if I had done the teachers a disservice in preparing them for a different kind of school context. Had I set them up for stress and additional challenge by promoting different instructional approaches and management choices? Was I partially responsible for their struggle? Did our program nurture the adaptive capacity necessary for any new teacher in their first years? After all, disconnect is to be anticipated between the preparation program and the first place of employment, no matter the schooling context.

Thus, at the end of year one, I worry that I may be responsible for some of the initial confusion, dissatisfaction, and friction unearthed in their first year in the field. However, as much as I am distressed about seeing young children sit rigidly in classrooms without ample time to relax their posture, the achievement data complicates the story. When one examines the school achievement data for these charter schools, the performance on the state language arts and math exams far exceeds the scores for the city and local district. The data included in Table 2 complicates the "means-to-an-end" argument and offers provocative and compelling evidence of academic performance above the comparison group and district performance.

\section{Table 2}

\section{Charter School Academic Performance Percent Passing ${ }^{2}$}

\begin{tabular}{|l|l|l|l|l|l|l|}
\hline & \multicolumn{3}{|c|}{ School A } & \multicolumn{3}{c|}{ School B } \\
\hline & School & $\begin{array}{l}\text { Comp } \\
\text { Group }\end{array}$ & District & School & $\begin{array}{l}\text { Comp } \\
\text { Group }\end{array}$ & District \\
\hline ELA & $79 \%$ & $67 \%$ & $24 \%$ & $81 \%$ & $68 \%$ & $20 \%$ \\
\hline Math & $78 \%$ & $69 \%$ & $24 \%$ & $78 \%$ & $69 \%$ & $14 \%$ \\
\hline
\end{tabular}

Emotional resilience. A second and related area of conflict centers on the novice teacher's ability to manage emotions and relationships within the schooling context. Both Paige and Penny were unprepared to address the compliance/resistance dilemmas that emerged in year one. While each situation offered unique and quirky personality issues, their stories suggest that new teachers may benefit from additional training in communication skills and emotion management in the navigation of workplace conflicts. Both reported conflict and tension with team leaders or supervisors who were insensitive and seemingly manipulative. Paige described her team leader who would email her from across the hall, rather than speak with directly. Penny was flummoxed when she was overlooked for the position of lead teacher, 
only later to find out that her supervisor did not want to lose her in the grade team, so did not inform her of the opportunity to shift roles. The areas of conflict resolution and navigating bureaucratic communication dilemmas are atypical curricular topics in educator preparation programs. However, this study asserts the importance of such training. The oft-cited 50\% dropout rate for new teachers may benefit from concerted effort to address such areas of emotional and social challenges.

This research study indicates new teachers may grapple with navigating school relationships during their first year in teaching and that this may be a primary and significant source of stress within the first-year context. Communication, feedback, and collaboration are vital aspects of teaching life. Particularly, in a school setting which challenges the news teacher's belief system and teaching philosophy so profoundly, it was apparent that the new teachers were not readily equipped with strategies to address such conflicts. In addition, challenging personalities, such as the supervisor with the "War Room," provided unexpected emotional management issues. This study has generated a new area of inquiry in teacher education: To what extent are EPPs responsible for preparing novice teachers to manage the emotional under-life of teaching? Is the induction process similar to any new place of employment, or are school relationship dilemmas particularly nuanced spaces requiring strategic intervention tactics and perspectives?

\section{Conclusion}

Given the issues we all know that await new teachers, it is important to pay more attention to developing, analyzing, and enacting strategies for navigation through emotional challenges in urban teaching so they can become sites of positive change, not negative impairment. (Chubbuck \& Zembylas, 2008, p. 310)

This research examines the emotional ebb and flow of new teachers in urban settings grappling with highly restrictive educational policy. Whether or not a new teacher is in a charter school, there will naturally be some "unlearning" and dissonance between the preparation program and the first place of employment (Hirsch, 2016). In Paige's portrait, we see an example of her compliance in context. "This is what I have to do to keep my job," she says. The portraits offer detailed understandings of firstyear emotional challenges. "Teachers must understand that in the school change process, conflict, tensions, and disturbance to long-held beliefs, ideologies and structures are inevitable and not to be feared" (Schmidt \& Datnow, 2005, p. 962). The varied changes the first-year teacher experiences are considerable. Should EPPs foreground the launch into our field by enhancing emotional resilience and adaptive capacity among our cohorts and their support networks? Is that even possible? This research is important in order to prepare, support, and retain qualified and caring instructors in schools that need them most.

\section{Notes}

1. Data retrieved from https://tools.nycenet.edu/dashboard.

2. Data retrieved from https://tools.nycenet.edu/dashboard. 


\section{References}

Achinstein, B., \& Ogawa, R. T. (2006). (In)Fidelity: What the resistance of new teachers reveals about professional principles and prescriptive educational policies. Harvard Educational Review, 76(1), 30-63.

Altinyelken, H. K. (2013). Teachers' principled resistance to curriculum change: A compelling case from Turkey. Global Managerial Education Reforms and Teachers, 109.

Angrist, J. D., Pathak, P. A., \& Walters, C. R. (2013). Explaining charter school effectiveness. American Economic Journal: Applied Economics, 5(4), 1-27.

Chubbuck, S. M., \& Zembylas, M. (2008). The emotional ambivalence of socially just teaching: A case study of a novice urban schoolteacher. American Educational Research Journal, 45(2), 274-318.

Dobbie, W., \& Fryer, R. (2011). Getting beneath the veil of effective schools: Evidence from New York City (NBER Working Paper 17632).

Gitlin, A., \& Margonis, F. (1995). The political aspect of reform: Teacher resistance as good sense. American Journal of Education, 103(4), 377-405.

Hargreaves, A. (2001). Emotional geographies of teaching. Teachers College Record, 106(6), 1056-1080.

Hirsch, M. (2016). Teach like a human: The reality gap in educator preparation. Schools: Studies in Education, 13(2), 339-348.

Hoxby, C., Murarka, S., \& Kang, J. (2009). How New York City's charter schools affect achievement. Cambridge, MA: New York City Charter Schools Evaluation Project.

Hoxby, C., \& Rockoff, J. (2005). The impact of charter schools on student achievement. Harvard Institute of Economic Research Working Paper Series.

Ingall, M. (2017, January 31). Protecting public schools: Why Jews should oppose Betsy DeVos's confirmation as Secretary of Education. Tablet. Retrieved from http://www.tabletmag.com/jewish-lifeandreligion/223101/protecting- publicschools

Lawrence-Lightfoot, S. (2005). Reflections on portraiture: A dialogue between art and science. Qualitative Inquiry, 11(1), 3-15.

Lawrence-Lightfoot, S., \& Davis, J. H. (1997). The art and science of portraiture. San Francisco, CA: Jossey-Bass.

McLaughlin, C. (2016, March 16). Low-graduation-rate schools concentrated in charter, virtual school sectors. NeaToday. Retrieved from http://neatoday.org/2016/05/16/low-graduation-rate-charter-virtualschools/

Mead, S. (2015, March 19). Charter score in cities: Urban charter schools are doing better than public ones, but can't always close the achievement gap. U.S. News and World Report. Retrieved from https://www.usnews.com/opinion/knowledge-bank/2015/03/19/new-study-shows-charter-schoolsmaking-a-difference-in-cities

National Alliance for Charters Schools. (2016, May 9). New report finds nearly half of charter high schools have excellent graduation rates; a subset underperforms. Retrieved from 
https://www.publiccharters.org/press/report-finds-charter-high-schools-excellent-graduation-ratessubset-underperforms

NYC Department of Education School Performance Dashboard. (2017). Retrieved from https://tools.nycenet.edu/dashboard/

Reddy, W. M. (2001). The navigation of feeling: A framework for the history of emotions. Cambridge, UK: Cambridge University Press.

Schmidt, M., \& Datnow, A. (2005). Teachers' sense-making about comprehensive school reform: The influence of emotions. Teaching and Teacher Education, 21, 949-965.

Spiro, R. J., Vispoel, W. P., Schmitz, J. G., Samarapungavan, A., \& Boerger, A. E. (1987). Knowledge acquisition for application: Cognitive flexibility and transfer in complex content domains. In B. C. Britton (Ed.), Executive control processes (pp. 177-199). Hillsdale, NJ: Lawrence Erlbaum.

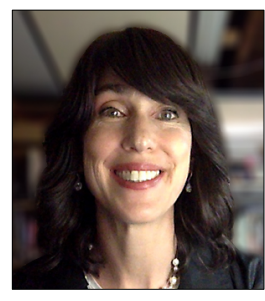

Miriam Hirsch is an Associate Professor of Education at Stern College for Women, Yeshiva University in New York City. Her research examines the influence of school stories in preservice teacher education. Her work has been published in Teaching Education, Educational Leadership, The Teacher Educator, The Educational Forum, Schools: Studies in Education, The Arts \& Humanities in Higher Education, The Journal of Jewish Education, and Jewish Educational Leadership. She enjoys tinkering with educational technologies and helping new teachers find their footing. 